\title{
Situación laboral de Administradores y Contadores egresados de la Universidad del Zulia
}

\author{
Narváez, Mercy \\ Fernández, Gladys \\ Vílchez, Nerio **
}

\section{Resumen}

La investigación reseñada en este artículo expone un análisis de la situación laboral de los egresados en Administración y Contaduría Pública de la Universidad del Zulia, específicamente del Núcleo Punto Fijo. Se estudia la condición laboral de estos profesionales, asi como también las necesidades de formación que estos manifiestan, en virtud de los requerimientos y exigencias del entorno. Reviste características de un estudio exploratorio y se previó para el mismo la aplicación de un diseño de campo. La población comprende a los egresados durante el periodo 1991-1998. Los resultados preliminares establecen la existencia de un grupo importante de estos profesionales desempleados y ocupando cargos distintos a los de su profesión, inclinándose un alto porcentaje a favor de la especialización en pregrado.

Palabras clave: Mercado de trabajo, situación laboral, administradores, contadores públicos, empleo, Universidad del Zulia.

\section{Recibido: 00-05-10, Aceptado: 00-10-13}

* Lic. en Administración. Mg. en Gerencia de Empresas. Profesora Asistente. Prog. Administración y Contaduría Pública Núcleo Punto Fijo. Universidad del Zulia. Venezuela. Teléfonos: 069-450512 Ext. 251. / 016-6692442.

** Lic en Contaduría Pública. Esp. en Contaduría. Profesora Asistente. Prog. de Administración y Contaduría Pública Núcleo Punto Fijo. Universidad del Zulia. E-mail: Jonash@ tutopia.com Graduado en Ciencias Pedagógicas de LUZ y Master of Arts (Educación) de la Universidad de Londres. Profesor Jubilado de la Universidad del Zulia.

Artículo basado en el proyecto de Investigación subvencionado por el CONDES "Mercado ocupacional de los egresados en Administración y Contaduría Pública del Núcleo LUZ Punto Fijo". 


\section{The Labor Situation of University of Zulia Graduates in Administration and Public Accounting}

\section{Abstract}

The research reported here offers an analysis of the labor situation of University of Zulia graduates in Administration and Public Accounting, specifically those graduated from the Punto Fijo Campus. The labor conditions of these professionals, as well as the needs for further academic formation as determined by their labor market are presented, This is an exploratory study and a field research design was applied accordingly. The population under study in this first part of the research corresponded to those who graduated between 1991 and 1998. The preliminary results establish the fact that many of these professionals are working in positions distinct from their professions, and a great number of them favor specialization in undergraduate studies.

Key words: Labor market, labor situation, administrators, public accountants, employment, University of Zulia.

\section{Introducción}

Las Universidades Nacionales se encuentran dentro de un proceso de cambios y transformaciones de orden social, político, económico y tecnológico que las orienta hacia la reorganización y reestructuración con el fin de adaptarse a tales cambios y generar respuestas que permitan cumplir con sus objetivos.

La Universidad del Zulia no escapa a los desafíos que muestra el entorno y percibe que para adaptarse a ellos debe convocar y propiciar una voluntad institucional que le permita la reordenación, yestablece que el desarrollo institucional debe provenir de un proceso de evaluación, a fin de garantizar su eficiencia y pertinencia social (C.U. LUZ, 1997:2).
Según 10 antes mencionado, se evidencia la necesidad de un continuo estudio de actualización curricular de las carreras que se imparten en LUZ, a fin de que estas se adapten y respondan al impacto de los cambios sociales y a los avances científicos, tecnológicos y humanisticos. Para lograr esto se contempla la evaluación interna y externa de los planes curriculares, de modo de actualizarlos de acuerdo a las necesidades y los adelantos de cada disciplina.

Esta situación origina la necesidad de realizar una investigación del mercado laboral de los egresados del Núcleo LUZ Punto Fijo en las carreras de Administración y Contaduria Pública, con el objeto de determinar su situación y condición laboral; las demandas y exigencias del sec- 
tor empleador y los distintos planes de desarrollo regional y local, a fin de establecer propuestas que satisfagan las necesidades de los distintos sectores y realizar los cambios pertinentes con el objeto de adaptar estas carreras a la realidad local, ya que las mismas se asumen y administran según lo establece la escuela de Administración y Contaduría Pública de la Facultad de Ciencias Económicas y Sociales de LUZ.

Este estudio se enmarca específcamente en la región de la Península de Paraguaná (sede del Núcleo LUZ); la cual es en los actuales momentos el más importante Centro de Refinación del mundo, además de ser Zona Franca Industrial y desde hace poco tiempo decretada Zona de Libre Comercio para el Fomento de la Inversión Turística. Estas características regionales exigen de la Universidad adaptaciones particulares, con el fin de satistacer los requerimientos de formación y capacitación del Recurso Humano, de forma tal que atienda y de respuesta a la realidad y especificidad regional.

En el presente artículo se presentan resultados parciales de la primera fase del estudio, los cuales se corresponden a la condición y situación laboral de los egresados en Administración y Contaduría Pública del Núcleo LUZ Punto Fijo en la Región Paraguaná.

\section{La necesidad de evaluar la Universidad del Zulia}

La actual coyuntura que experimentan las universidades venezolanas, debido a una política presupuestaria deficiente y mal instrumentada, así como la inviabilidad del modelo universitario para responder con eficiencia a los cambios a nivel mundial, nacional y regional, le demanda a La Universidad del Zulia una nueva visión que le permita buscar nuevas direcciones estratégicas conducentes a su transformación con bases innovadoras.

En esa línea de pensamiento LUZ ha empezado a recorrer el camino que facilitará ese proceso de transformación y para ello establece lo siguiente:

1) La Resolución del C.U. No. 336, (2304-97) es el instrumento que establece la base legal para el proceso de transformación y tiene como prioridad la reorganización académicoadministrativa como parte de un proceso de reorganización institucional que permitirá a partir de un conocimiento profundo y efectivo de la Institución, fundamentar las respuestas a los desafíos y demandas actuales.

2) La Filosofía de Gestión Institucional (08-10-97) que expresa la doctrina fundamental de gestión, asi como sus modalidades de acción en el contexto de la nueva visión de la universidad que se quiere, es decir, una Institución de Excelencia Académica con Compromiso Social.

3) El Plan de Desarrollo Estratégico (16-09-98), el cual permitirá direccionar el esfuerzo institucional, imponiendo un rumbo a los acontecimientos en función de los objetivos perseguidos, siempre enmarcados en el contexto teleológico definido en la $\mathrm{Fi}$ losofía de Gestión. 


\section{Relación de la Universidad con el mercado de trabajo}

Las instituciones universitarias, además de formar ciudadanos o científicos, forman profesionales $y$, desde luego, los considerables gastos que las sociedades dedican a la enseñanza superior, carecerían de sentido y legitimidad si se deja de creer que estas instituciones forman los profesionales que la sociedad demanda (Espinoza, 1993: 33).

En cuanto a la estructura de las carreras de estudios que ofrece y la cantidad de egresados que genera cada una de las Facultades, estamos frente a una institución cuyo cometido se ve perjudicado por dos tipos de demandas externas, una que se concentra en mayores y mejores oportunidades de estudio y otra, en cuanto a la mejor calificación para atender las solicitudes de profesionales originadas de los distintos sectores empleadores (Espinoza, 1993: 37).

Así pues, LUZ debe estar preparada a dar respuestas a dichas necesidades, teniendo en cuenta que se puede afectar la capacidad de satisfacer los requerimientos de empleos.

La decisión de transformar una carrera profesional y la de crear otras, debe estar soportada por un proceso de investigación y análisis enmarcados en un proceso de planificación para la formación de recursos humanos, que evite deficiencias y limitaciones tales como: imprecisión en los roles profesionales, sustituibilidad de profesionales, desequilibrios en el mercado de trabajo, futuro ocupacional de los egresados, exceso ocupacional de los egresados, exceso de especialistas con calificaciones inadecuadas (Espinoza, 1993:37). El se- guir ofertando egresados debe ser planificado por las universidades de manera tal que no se sature el mercado.

La idea expuesta es de suma importancia a la hora de ofrecer alternativas de profesionalización, en el entendido que no se deben graduar profesionales para el desempleo y el subempleo. Es evidente que, para muchos titulados universitarios, la principal causa del desempleo y subempleo, deriva de la insuficiente creación de empleos y que en períodos de crisis como el que vive el pais, tiende a afectar sobremanera a los recién ingresados al mercado de trabajo. De manera tal que, por tratarse de una situación coyuntural de orden económico, no se puede cerrar o regular el acceso a la universidad, en primer lugar, porque ello sólo tendrá efecto sobre el desempleo en el mediano y largo plazo, y para entonces bien podríamos encontrarnos en situaciones de crecimiento económico; en segundo lugar, porque la situación de desocupación responde igualmente a factores de naturaleza social y politica generados por el propio sistema económico del país (Espinoza, 1993: 39).

\section{Estructura curricular del pregrado y capacidad de absorción de egresados del mercado ocupacional}

En los últimos años Venezuela ha vivido un severo proceso de contracción económica caracterizado por grandes deudas en el exterior cuya negociación pone incluso en tela de juicio nuestra autonomia e independencia nacional, desempleo con inflación, carestía y especu- 
lación de alimentos y mercaderías, todo ello con sus secuelas sociales: descomposición de los servicios públicos, y una constante improductividad de la burocracia oficial, particularmente en el estímulo a las actividades agrícolas, industriales $y$ agroindustriales. Las profesiones universitarias no están al margen de la crisis: los niveles de desocupación y sub-empleo profesional se pueden intensificar agudamente en los próximos años.

Por esta via, la enfermedad económica y social termina devaluando los títulos profesionales, e influye en el aparecimiento y desarrollo de la "enfermedad del diploma" la cual, a su vez, agrava la primera porque la Educación Superior consume ingentes recursos nacionales que resultan invertidos en capacitación de Recursos Humanos cuyo destino final, después del grado, es la frustración del desempleo o subempleo.

Para mejorar esta crisis es factible en el plano de la formación profesional, combinar una educación polivalente con la exploración de carreras nuevas, sobre la base de la autogestión y la gerencia cooperativa de pequeñas y medianas unidades de producción.

Hay orientaciones a volver a una formación más integral, atendiendo los cambios económicos y sociales que revierten en la incapacidad de absorber egresados por parte del mercado ocupacional, genera una mayor dependencia de la Universidad frente a la sociedad. Se argumenta que la Universidad no puede estar permanentemente a la saga de su entorno, sino más bien a su vanguardia; que la Universidad ha de ser guía y faro de la sociedad y para ello es necesario que profesionalice a sus alumnos lo más posible. Este argumento afirma que si se acentúa la crisis, entonces hay que profesionalizar más al graduado para que su aporte cientifico y tecnológico coadyuve a la solución de la crisis. Pero no necesariamente una cosa conduce a la otra: no por más calificación científica y técnica va el recién egresado a desarrollar una conciencia crítica y a sentirse socialmente comprometido con el destino del país.

La polémica sobre si la Universidad es vanguardia o retaguardia de la transformación social es una discusión inocua e infructífera. De ciento lo único que se sabe son dos cosas. Primero, que todo proceso educativo es legitimador de las circunstancias sociales, que la educación coopera en la implantación del proyecto social previamente concebido por las elites del Estado, y por lo tanto, que su capacidad para contribuir en un proceso de cambio social está supeditada al proyecto que procuren los centros de poder y decisión social.

$Y$ segundo, que en paises en desarrollo como Venezuela la educación ha constituido hasta ahora un instrumento idóneo para el ascenso social de sus usufructuarios, premisa ésta que queda en entredicho precisamente cuando el marco económico y social convulsiona, cuando la crisis estalla, la depresión profundiza y la cesantía profesional se hace presente. De esta manera retornamos al punto de origen en una elipse desafiante: como no existe un proyecto nacional de reconstrucción, la crisis se agudiza y alcanza negativas consecuencias a la formación de los cuadros profesionales; incluso cabe pensar si la relación curriculum/empleo no escapa de lo meramente coyuntural y si la determinación de los ni- 
veles de generalidad/especialización en los estudios de pregrado no es un asunto sustantivo en la planificación de la educación superior, un tanto independientes del marco económico de la sociedad.

Es obvio que mientras mayor sea la especialización más rápidamente se satura esa área especifica de empleo. Esto nos sugiere que la decisión curricular por una formación más generalista o más especializada aunque está influenciada por la circunstancia económica se escapa de ella y más bien se adviene con un dictamen estructural: el pregrado es para la generalización, restringida al perimetro natural de la profesión y el postgrado es para la especialización y profundización en un área de la misma (Vílchez, 1985: 27-33).

Las carreras universitarias deben ser rediseñadas en función de procesos de "Reingeniería", la cual se define como: revisión fundamental y rediseño radical para alcanzar mejoras espectaculares en medidas críticas y contemporáneas de rendimiento, tales como costos, calidad, servicio y rapidez (Hammer y Champy, 1995:33). Pero a la par de la revisión que debe realizar la universidad de las carreras, las empresas y organizaciones también deben hacerlo con el objeto de cambiar sus procesos internos y otros aspectos organizacionales.

Entre los tipos de cambios que ocurren cuando una organización rediseña sus procesos se encuentran:

- Los oficios cambian de tareas simples a trabajo multidimensional.

$A$ veces la reingenieria cambia las fronteras entre distintas clases de traba- jo. El oficio se vuelve más multidimensional y más sustantivo, además el trabajo se hace mas remunerador, porque los oficios adquieren un mayor componente de desarrollo personal y aprendizaje. Oficios complejos para gente capacitada, lo cual eleva la barrera para entrar en la fuerza laboral. En un ambiente rediseñado quedan muy pocos oficios sencillos, de rutina, no calificados (Hammer y Champy, 1995:73-74).

- La preparación para el oficio cambia: de entrenamiento a educación.

Los empleados necesitan suficiente educación para discernir que es lo que deben hacer. Las compañias tradicionales hacen hincapié en entrenar a los empleados, es decir, enseñarles a realizar determinado oficio o a manejar una situación específica. El entrenamiento aumenta las destrezas y la competencia y les enseña a los empleados el "cómo" de un oficio; la educación aumenta su perspicacia y la comprensión y les enseña el "por qué".

Para oficios multidimensionales y cambiantes las empresas no necesitan personas para llenar un puesto porque el mismo está solo vagamente definido. Necesitan gente que entienda en qué consiste el oficio y sea capaz de realizarlo, gente capaz de crear el empleo que se le acomode; además, el empleo seguirá cambiando. En un ambiente de cambio y flexibilidad, es claramente imposible contratar personas que ya sepan absolutamente todo lo que necesitan saber, de modo que la educación continua durante toda la vida del oficio pasa a ser la norma en una compañía rediseñada (Hammer y Champy, 1995: 76-77). 


\section{Discusión y Análisis}

La Universidad del Zulia en Punto Fijo se inició como un compromiso con la capital económica del Estado Falcón, dado que en esta ciudad de rápido desarrollo económico-social estaban presentes dos de las más grandes refinerias de petróleo de Venezuela: Amuay y Cardón, hoy día integradas y convertidas en un importante centro de refinación mundial denominado "Complejo Refinador de Paraguaná".

Estas empresas exigian en aquel momento que su personal se capacitara y profesionalizara, en especial en el área administrativa y es asi como el 01 de noviembre de 1959 se comienzan a dictar materias de la carrera de Administración y Contaduria Pública, como una extensión de la carrera que se ofrecía en Maracaibo. Ello implicaba el traslado del personal docente de Maracaibo a Punto Fijo hasta tanto no se contara con una propia planta profesoral.

Es así como la Escuela de Administración y Contaduría Pública comienza a tener sus propios egresados a partir del año 1964 hasta nuestros días, en una labor ininterrumpida durante cuarenta (40) años, con las modificaciones curriculares que se establecen desde la Facultad de Ciencias Económicas y Sociales en Maracaibo.

En 1994 es aprobado el proyecto de convertir la extensión de la Universidad del Zulia en Punto Fijo en Núcleo Decanal, éste se inicia en el contexto de una crisis, que a veces parece permanente tanto en el ámbito social como en el subsistema de Educación Superior, pero a pesar de esta situación el Núcleo LUZ Punto Fijo nace con optimismo, enmarca- do en una sociedad nacional y circunstancialmente en la comunidad universitaria reestructurada en Punto Fijo.

La Filosofía de Gestión del Núcleo LUZ Punto Fijo establece como objetivo desarrollar un proceso de formación integral de profesionales altamente competitivos que respondan a la realidad regional y a las exigencias de un mundo global, asumiendo el rol de vanguardia tecnológica, para ello se deben proponer alternativas curriculares flexibles centradas en la cooperación educativa para responder a las necesidades del entorno. Por otra parte, el Núcleo se propone inducir la demanda de oportunidades de estudio hacia áreas prioritarias del desarrollo regional y nacional.

En el Núcleo LUZ Punto Fijo se deben realizar evaluaciones permanentes de los diseños curriculares que administra, con el objeto de tomar decisiones sobre el desarrollo académico del mismo, esto obedece al carácter experimental que tiene el Núcleo, contemplado en el artículo 61 del Reglamento de Núcleos de la Universidad del Zulia que expresa:

Se establece un período de cinco años, a partir de la fecha de aprobación del Consejo Nacional de Universidades (1993), para evaluar el funcionamiento y estructura de los Núcleos y la pertinencia de los programas curriculares, $y$ un período máximo de dos años, para que cada Núcleo presente propuestas alternativas a los programas curriculares actuales.

Desde el año 1994 se vienen adelantando estudios en el área curricular con la finalidad de presentar propuestas de nuevas carreras. Para ello se han realizado investigaciones que demuestran 
Situación laboral de Administradores y Contradores egresados de LUZ Narváez, M.; Fernández, G. y Vilchez, N.

su factibilidad y pertinencia social. Enmarcados en estas investigaciones, se está realizando este estudio a los egresados en las carreras de Administración y Contaduria Pública del Núcleo LUZ Punto Fijo, durante el período 1991-1998, con la finalidad de conocer su condición y situación laboral. Se aplicó una encuesta a una muestra de 110 Lic. en Administración y 147 Lic. en Contaduría Pública, elegidos de manera probabilistica a través de una selección aleatoria dentro de una población de 332 egresados en Administración y 442 en Contaduria Pública, encontrándose lo siguiente:

En lo que corresponde a la situación laboral de los egresados en Administración del Núcleo Punto Fijo, el 55,45\% de la muestra se encuentra empleado, es decir perciben una remuneración fija y ocupan cargos relacionados con su formación y su profesión. El 17,27\% se encuentra ocupando cargos distintos a su profesión, es decir están subempleados y el $27,27 \%$ no se desempeña en ninguna área, ya que no poseen trabajo. En cuan- to a la muestra de los egresados en Contaduría, el 76,19\% está ocupando cargos relacionados con su profesión, el 13,61\% está subempleado y el $10,20 \%$ no está laborando.

En conjunto, la situación laboral de los egresados de las carreras de Administración y Contaduría Pública durante el período $91-98$ es la siguiente: el $67 \%$ está empleado, el $15 \%$ está subempleado y el $18 \%$ está desempleado. (Ver gráfico 1). Lo que puede justificar que los Contadores se empleen más que los Administradores, es el hecho de que muchos de los Contadores ejercen la función de Administradores, ya que si bien tienen roles definidos dentro de su profesión, de acuerdo a la formación recibida se desempeñan también en los roles de los Administradores, aún cuando su formación no es polivalente. No es extraño conseguir a un Contador como Gerente, Administrador, Empresario o Consultor, pero rara vez se consigue a un Licenciado en Administración como Auditor, Contralor o Consultor.

\section{Gráfico 1}

Situación laboral de los egresados del programa de Administración

y Contaduría del Núcleo LUZ Punto Fijo

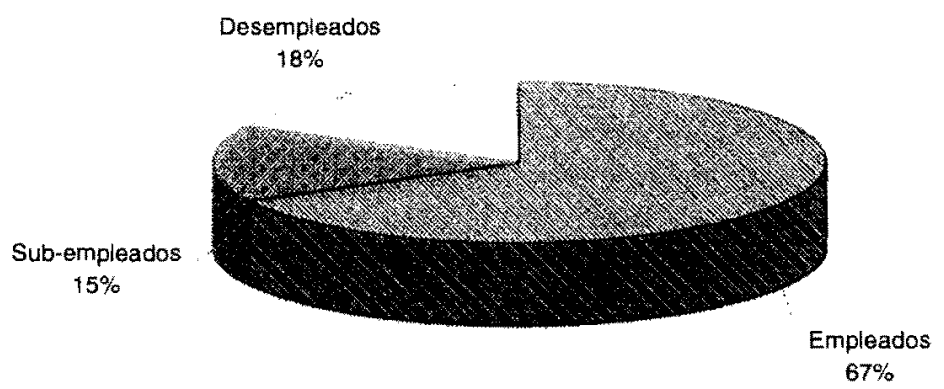

Fuente: Encuesta realizada a los egresados en Administración y Contaduria Pública del Nủcleo LUZ Punto Fijo. 
El área común de formación entre Administradores y Contadores es muy amplia, razón esta que permite que en muchos casos el sector empleador no perciba diferencias claras entre ambos profesionales, y se derive de esta situación que sea indistinto contratar o emplear a un Administrador o a un Contador para un cargo en particular, lo que implica que se deben diferenciar al máximo el diseño curricular de estas carreras, a tin de formar profesionales con pertiles distintos que respondan a las necesidades particulares del mercado de trabajo.

Además, debe tomarse en cuenta la estructura ocupacional, la cual se define como los diversos sectores de la actividad económica y de los servicios en los cuales se inserta la fuerza de trabajo calificada. Se debe suponer que para cada profesión hay un mercado de trabajo donde existe una clara delimitación y precisión de los puestos laborales (Espinoza, 1992:40). Es importante conocer el funcionamiento del mercado de trabajo, a fin de determinar en que cargos y en que tareas se desempeñan los profesionales de Administración y Contaduría Pública, ya que se da el caso que en las empresas y organizaciones las características de los cargos no son muy precisas para discriminar las competencias de estos profesionales en función del perfil profesional de cada uno de ellos.

Del total de la población subempleada o desempleada en ambas carreras, el $58 \%$ indica que la razón por la cual no ejercen cargos relacionados con su profesión es porque hay pocas oportunidades de empleo en su área, destacándose el hecho de que de este porcentaje, el $41 \%$ corresponde a Administradores y el $17 \%$ a Contadores, 10 que apo- ya la hipótesis planteada de que los Contadores en el campo laboral ocupan el área de los Administradores. El $27 \%$ de los encuestados opina que no ejercen por los bajos salaros que se perciben. Un porcentaje muy pequeño $(4 \%)$ considera que no posee disponibilidad para trasladarse fuera de la zona y el $11 \%$ indica que es por otras razones, entre las cuales se destaca el hecho de que ocupan cargos no relacionados con su profesión desde antes de graduarse y no han sido promovidos dentro de las empresas en las cuales laboran.

En lo referente a la condición laboral de los egresados que se encuentran empleados y subempleados, el $3 \%$ está ubicado en el sector primario de la economía (Agricultura y Pesca), el $18 \%$ en el sector secundario correspondiente a la Industria y construcción y el $79 \%$ está laborando en el sector terciario o de servi* cios; el alto porcentaje de egresados que se observa en este sector se debe al hecho de que en la región Paraguaná la mayor parte de las empresas se encuentran ubicadas en el mismo (Ver gráfico 2).

En lo que corresponde a la forma de trabajo la modalidad que predomina es la dependiente, tanto para los egresados en Administración como en Contaduría, dada la cultura del salario que existe en nuestro país en donde las personas antes de formar su propia empresa o negocio, o trabajar por cuenta propia prefieren que alguien las emplee, garantizando de alguna forma niveles de ingreso estables, aún cuando ambos profesionales están en capacidad de trabajar de manera independiente.

Los cargos que ocupan los egresados empleados y subempleados en el área de Administración se muestran en la Tabla 1. 
Situación laboral de Administradores y Contradores egresados de LUZ Narváez, M.; Fernández, G. y Vilchez, N.

\section{Gráfico 2}

Sectores de la economía donde se desempeñan los egresados del Núcleo LUZ Punto Fijo del Programa de Administración y Contaduría Pública

$$
\text { Terciario } 79 \%
$$

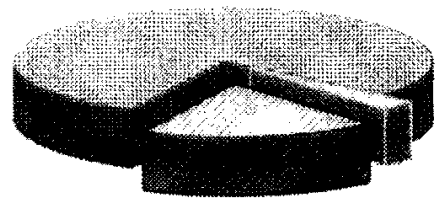

Primario $3 \%$

Secundario $18 \%$

Fuente: Encuesta realizada a los egresados en Administración y Contaduría Pública del Núcleo LUZ Punto Fijo.

Es necesario mencionar que los Administradores subempleados (23\%), están ocupando cargos relacionados con el comercio, cobranzas, entre otros. (Ver gráfico 3). En el caso de los egresados en Contaduría empleados y subempleados, estos ocupan los cargos que se indican en la Tabla 2.

De estos profesionales los subempleados (15\%) son los que ocupan cargos tales como Auxiliar de Cobranza, Coordinador de servicios. (Ver gráfico 4)

Cabe destacar que los servicios profesionales de los egresados en Administración y Contaduría son muy similares, se desempeñan en los actuales momentos de manera indistinta como Administradores, Contadores, Asistentes administrativos, Asistentes Contables, Gerentes, Docentes en el área Administrativa y Contable, también se desempeñan en el área de Seguro y Cobranzas. Esto implica la adecuación necesaria de los diseños curriculares a fin de diferenciar los rasgos y el perfil de cada uno de estos profesionales.

En lo que se refiere a los roles que desempeñan los profesionales de Administración empleados, se puede reseñar lo siguiente: el $62,30 \%$ ejecuta el rol de Administrador, cuya función es la de planificar, organizar, dirigir y controlar los recursos de la organización para alcanzar los objetivos de la misma; el $\mathbf{9}, \mathbf{8 4} \%$ se desempeña en el rol de Gerente, orientado a liderar los procesos organizacionales para garantizar el logro de los objetivos; el $4,92 \%$ ocupa el rol de empresario, es decir como creador $y$ lider de proyectos y programas de negocios, a nivel de la mediana y pequeña empresa; el 4,92\% se ubica en el rol de Consultor Administrativo y Gerencial, desempeñándose en actividades de asesoría de gestión, a través de la investigación, diseño y evaluación de procesos en las organizaciones; $y$ el $18,03 \%$ se desempeña en otro rol. (Ver gráfico 5). 


\section{Tabla 1}

Cargos desempeñados por los egresados en Administración

\begin{tabular}{lrr|lrr}
\hline Cargos & fa & $\%$ & Cargos & fa & $\%$ \\
Administrador & 19 & 23 & Asistente Tesoreria & 3 & 4 \\
Asistente Administrativo & 12 & 14 & Contador & 2 & 3 \\
Gerente & 6 & 8 & Asistente contable & 3 & 4 \\
Empresario & 3 & 4 & Docente & 6 & 8 \\
Asesor Financiero & 3 & 4 & Otros & 19 & 23 \\
Jefe de Unidad & 4 & 5 & TOTAL & 80 & 100 \\
\hline
\end{tabular}

Fuente: Encuesta realizada a los egresados en Administración y Contaduría Pública del Núcleo LUZ Punto Fijo.

\section{Gráfico 3}

Cargos que ejercen los egresados de Administración del Núcleo LUZ Punto Fijo

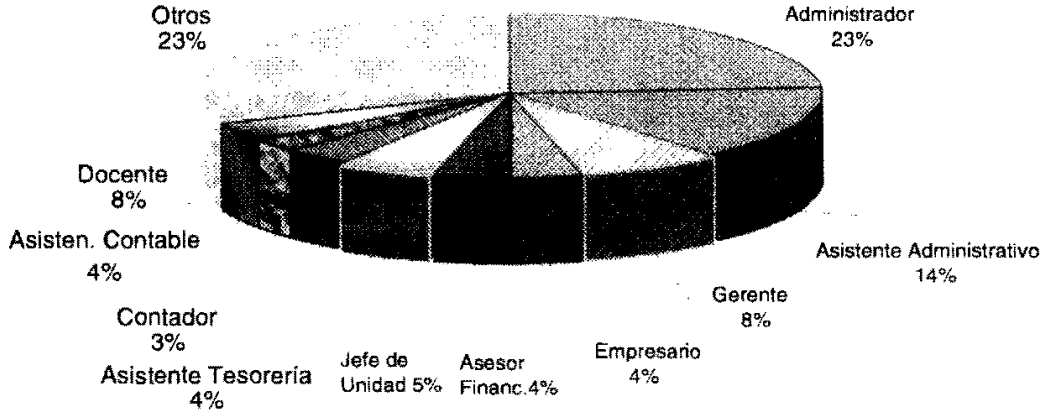

Fuente: Encuesta realizada a los egresados en Administración y Contaduría Pública del Núcleo LUZ Punto Fijo.

Tabla 2

Cargos desempeñados por los egresados en Contaduría Pública

\begin{tabular}{lrr|lrr}
\hline Cargos & fa & $\%$ & Cargos & fa & $\%$ \\
Administrador & 27 & 20 & Asistente contable & 5 & 4 \\
Contador & 59 & 45 & Analista de costos & 4 & 3 \\
Gerente & 5 & 4 & Docente & 8 & 6 \\
Asistente administrativo & 4 & 3 & Otros & 20 & 15 \\
& & & TOTAL & 132 & 100 \\
\hline
\end{tabular}

Fuente: Encuesta realizada a los egresados en Administración y Contaduría Pública del Núcleo LUZ Punto Fijo. 
Situación laboral de Administradores y Contradores egresados de LUZ Narváez, M.; Fernández, G. y Vilchez, N.

\section{Gráfico 4}

Cargos que ejercen los egresados de Contaduría Pública del Núcleo LUZ Punto Fijo

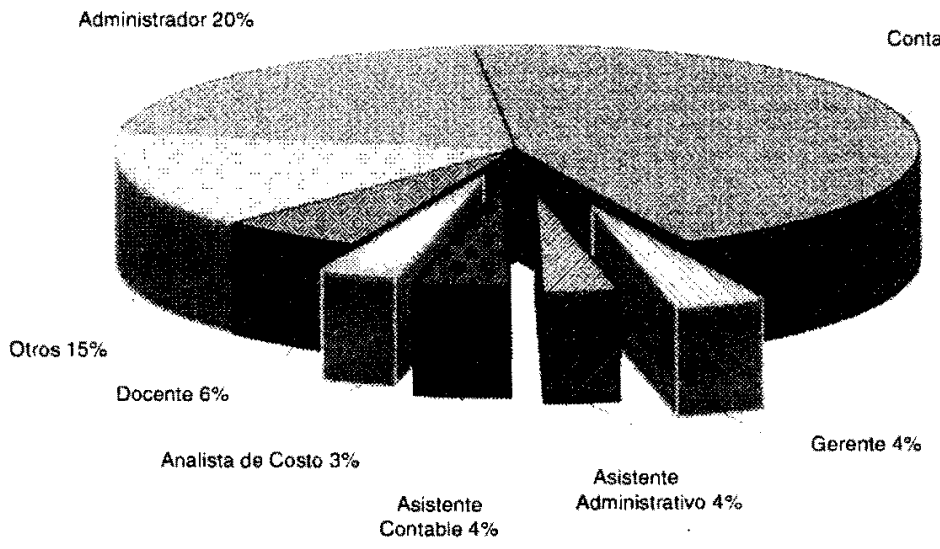

Fuente: Encuesta realizada a los egresados en Administración y Contaduria Pública del Núcleo LUZ Punto Fijo.

En cuanto a los roles de los Contadores, el $12,50 \%$ de la muestra que se encuentra laborando se desempeña como Contralor, es decir, establece sistemas, métodos y procedimientos de control sobre las actividades contables, financieras, presupuestarias, tributarias y legales; el $7,14 \%$ está como Auditor, es decir, examina de acuerdo con normas de auditoría de aceptación general, los estados financieros de una entidad, con el fin de obtener evidencia suficiente y competente como base para emitir una opinión; el 8,04\% está como Consultor. es decir, asesora a organizaciones púbiicas o privadas; el $33,04 \%$ se desempeña como Contador ejecutando todos los roles anteriores (Contralor, Auditor y Consultor) y el $39,29 \%$ desempeña otros roles relacionados con la profesión, tales como Gerentes y Administradores. (Ver gráfico 6).
El rol de Contador no se encuentra especificado como tal en el Perfil Profesional del Licenciado en Contaduría Pública, sin embargo, se considera necesario incluirlo como uno más, ya que se da con extremada frecuencia que los egresados en esta carrera se desempeñen de manera simultánea en el ejercicio de sus funciones como Contralor, Auditor y Consultor.

El total de encuestados tanto de la carrera de Administración como de Contaduría califican en un $15,95 \%$ que la formación recibida en LUZ para el desempeño de su trabajo es excelente, el $65,37 \%$ la considera buena y sólo el $18,68 \%$ manifiesta que es regular. Sin embargo, cuando se les preguntó a los egresados en Administración acerca del tipo de formación que la Universidad del Zulia debe impartir, el $4,28 \%$ considera que debe ser generalista y el $38,52 \%$ especializado. En 


\section{Gráfico 5}

Roles que desempeñan los egresados en Administración del Núcleo LUZ Punto Fijo

Administrador $62,30 \%$

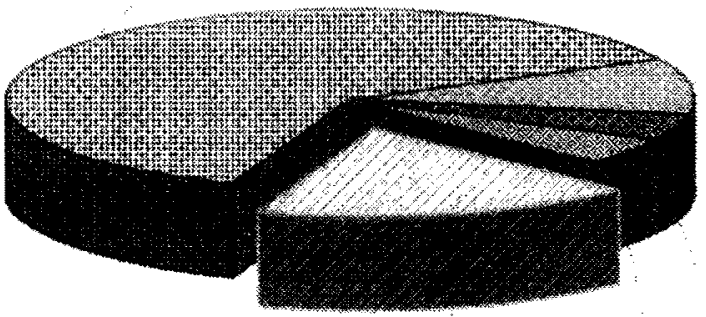

Gerente $9,84 \%$

Empresario 4,92\%

Otros $18,03 \%$

Consultor $4,92 \%$

Fuente: Encuesta realizada a los egresados en Administración y Contaduria Pública del Núcleo LUZ Punto Fijo.

\section{Gráfico 6 \\ Roles que desempeñan los egresados en Contaduría del Núcleo LUZ Punto Fijo}

Consultor $8,04 \%$

Todos los anteriores $33,04 \%$

Auditor $7,14 \%$

Contralor $12,50 \%$

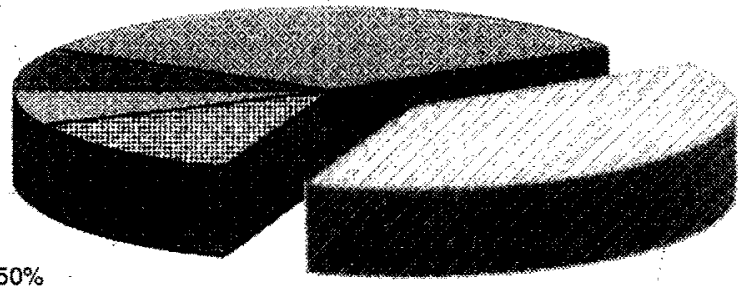

Cargos Administrativos $39,29 \%$

Fuente: Encuesta realizada a los egresados en Administración y Contaduria Pública del Núcleo LUZ Punto Fijo. 
Situación laboral de Administradores y Contradores egresados de LUZ Narváez, M.; Fernández, G. y Vilchez, N.

cuanto a los egresados en Contaduría, estos opinan en un $17,51 \%$ que debe ser generalista y el $39,69 \%$ se inclina a favor de la especialización. Con respecto a la especialización los Administradores y los Contadores coinciden en que esta debe darse en Pregrado $(70,71 \%$ y $62,75 \%$, respectivamente), en las siguientes áreas, por orden de opciones:

1) Tributación e Impuestos

2) Exportación//mportación/Aduanas

3) Turismo

4) Recursos Humanos

Se percibe una alta tendencia tanto de los Administradores como de los Contadores hacia la necesidad de especialización en el nivel de Pregrado, esto viene dado en virtud de la dinámica y cambiante situación que se presenta tanto a nivel nacional como regional. El hecho de la formulación de una política fiscal tributaria a largo plazo por parte del estado venezolano requiere de profesionales formados en esta área, y los Administradores y Contadores son algunos de los profesionales llamados a prepararse en este aspecto. Por otra parte, la creación de la Zona de Libre Comercio para el Fomento de la Inversión Turística en Paraguaná origina la necesidad de profesionales con formación en turismo y en el área de Importación/Exportación/Aduanas.

Los egresados del Núcleo LUZ Punto Fijo en las carreras objeto de estudio de este trabajo, perciben de manera clara la necesidad de estar capacitados en algunas o varias de estas áreas, de modo de garantizarse un lugar en el mercado laboral de la región.

\section{Consideraciones Finales}

La situación laboral de los egresados del Núcleo LUZ Punto Fijo, durante el período 1991-1998 es la siguiente: sólo el $55,45 \%$ de los Licenciados en Administración y el $76,19 \%$ de los Contadores están empleados, encontrándose que en algunos casos los Licenciados en Contaduría ejercen la función de Administradores, ya que si bien estos tienen roles definidos dentro de su profesión, de acuerdo a la formación recibida, pueden desempeñar también los roles de los Administradores. Además de esto, es más rentable para una organización pública o privada emplear a un Contador que pueda realizar las funciones propias de Contabilidad y Contraloría y además, ejercer labores en el área de Administración.

La mayoría de los egresados en las carreras de Administración y Contaduría Pública, que se encuentran em. pleados o subempleados, se ubican en el sector terciario, encontrándose que muy pocas veces asumen el reto para asociarse con otros profesionales con el objeto de ofrecer sus servicios, formar sus propios proyectos o programas de negocios y trabajar por cuenta propia ya que prefieren ser empleados en organizaciones establecidas.

Dada la situación laboral de estos profesionales y aunado al hecho de la creación de la Zona de Libre Comercio para el Fomento de la Inversión Turística en Paraguaná, los egresados se inclinan a favor de la especialización en el pregrado, orientando sus prioridades a las áreas de Tributación e Impuestos, Exportación/Importación/Aduanas, Turismo y 
Recursos Humanos. Se plantea como propuesta para la demanda de estos profesionales la creación por parte del Núcleo LUZ Punto Fijo de "programas", los cuales se definen como conjunto ordenado de actividades relacionadas con el análisis y formulación de alternativas de solución a los problemas nacionales, regionales, subregionales y locales (Universidad del Zulia,1993:17), los programas deben tener una duración variable, matricula controlada y enseñanza "in situ". Para satisfacer estos requerimientos, tales programas deben agotarse después de ciertas cohortes.

Por otra parte, las carreras de Administración y Contaduría deben reformularse para responder al futuro económico de la región, de manera tal que en pregrado, debe reforzarse el Plan de Estudios en ambas carreras.

Se debe ofrecer en ambos casos la prosecución de estas carreras en el Postgrado, tanto a nivel de especialización como de maestría, lo que exige al Núcleo LUZ Punto Fijo la adecuación de su recurso humano e instalaciones, a fin de garantizar una respuesta efectiva a las necesidades que demandan los egresados en las carreras objeto de estudio.

\section{Bibliografía citada}

Congreso de la República (1982). Ley del ejercicio de la profesión del Licenciado en Administración. Caracas.

Congreso de la República (1973). Ley del ejercicio de la profesión del Licenciado en Contaduria Pública. Caracas.

Espinoza, Rafael (1992). Estudios de Mercados de Trabajo. Creación de Nuevas Profesiones. Fondo Editorial
Esther Maria Osses. Universidad del Zulia. Facultad de Humanidades y Educación. Maracaibo, Venezuela

Espinoza, Rafael (1993). El Estudio de Mercados de Trabajo en el contexto de la Planificación de las carreras profesionales y la oferta de recursos humanos por las Instituciones de Educación Superior. Revista Espacio Abierto. Cuaderno Venezolano de Sociología. Año 2. No. 4. pág. 33-50. Maracaibo, Venezuela.

Hammer, Michael y Champy James (1995). Reingeniería. Grupo Editorial Norma.

Universidad del Zulia (1993). Reglamento de Núcleos. Maracaibo, Venezuela.

Universidad del Zulia (1994), Facultad de Ciencias Económicas y Sociales. Plan Curricular Licenciatura en Administración. Maracaibo, Venezuela.

Universidad del Zulia (1994). Facultad de Ciencias Económicas y Sociales. Plan Curricular Licenciatura en Contaduría Pública. Maracaibo, Venezuela.

Universidad del Zulia (1997). Lineamientos Conceptuales para el Proceso de Evaluación Institucional en LUZ. (Resolución 336). Maracaibo, Venezuela.

Universidad del Zulia (1997). Filosotia de Gestión. Maracaibo, Venezuela.

Universidad del Zula. Núcleo Punto Fijo (1998). Filosofía de Gestión. Punto Fijo, Venezuela.

Universidad del Zulia (1998). Plan de Desarrollo Estratégico. Maracaibo, Venezuela.

Vílchez, Nerio (1985). Estructura curricular del pregrado y capacidad de absorción de egresados del mercado ocupacional Revista Opción. Año 2. No. 3, pág. 27-33. Revista del Departamento de Ciencias Humanas de la Facultad de Ciencias de La Universidad del Zulia. Maracaibo, Venezuela. 